\title{
Clinical Utility of the Meal Tolerance Test in the Care of Patients with Type 2 Diabetes Mellitus
}

\author{
Hisao Wakasaki, Takeshi Shono, Ryutaro Nakao, Shohei Yamamoto, Takamasa Minaga, \\ Sakiko Fukuda, Reika Matsumoto, Takashi Ohoshi, Keigo Naka and Kishio Nanjo
}

\begin{abstract}
:
Objective The measurement of C-peptide immunoreactivity (CPR) is essential for evaluating the pancreatic $\beta$-cell function and selecting appropriate therapeutic agents in patients with diabetes mellitus. The meal tolerance test (MTT) is simple to administer physiological insulin-stimulating test. Previous studies have reported that several CPR-related indices are useful markers for predicting insulin requirement in type 2 diabetes. In the present study, we investigated the serum CPR response during the MTT in hospitalized patients with type 2 diabetes mellitus in order to clarify the clinical utility of the MTT.

Methods We performed the MTT using a test meal with timed measurements of the serum CPR level based on the oral glucose tolerance test over 180 minutes and tested the correlation of various CPR-related indices and clinical factors in patients with type 2 diabetes mellitus.

Patients The subjects were patients with type 2 diabetes mellitus who had been admitted to our hospital for diabetes management and education. The final study population consisted of 68 patients.

Results The fasting CPR level was correlated with the 24-hour urinary CPR excretion and body mass index. The serum CPR level at 120 minutes in the MTT was strongly correlated with the area under the curve of CPR during the MTT. The patients who needed insulin therapy at 6 months after hospitalization showed a significant lower incremental CPR value from 0 to 120 minutes in the MTT than those who did not need insulin therapy.

Conclusion The plasma C-peptide levels at 0 and 120 minutes in the MTT provide essential information for the clinical management of patients with type 2 diabetes mellitus.
\end{abstract}

Key words: meal tolerance test, C-peptide, type 2 diabetes

(Intern Med 59: 2229-2235, 2020)

(DOI: 10.2169/internalmedicine.4591-20)

\section{Introduction}

Type 2 diabetes is characterized by impaired insulin action and decreased insulin secretion. Insulin secretion from pancreatic $\beta$-cells decreases with the duration of type 2 diabetes. The inability of the $\beta$-cells to compensate for insulin resistance can be a primary cause of type 2 diabetes. It is important to evaluate the insulin secretion capacity in diabetes patients in order to establish the appropriate treatment. Insulin is secreted from pancreatic $\beta$-cells via portal vein, then rapidly extracted by the liver. The serum immunoreactive insulin (IRI) level is markedly influenced according to the clearance of insulin in the liver. The measurement of the C-peptide immunoreactivity (CPR) in response to a stimulus provides a direct measure of the $\beta$-cell function. The serum CPR value, rather than IRI, is useful for assessing the endogenous insulin secretion, especially in insulin-treated patients (1).

Two methods are generally used in clinical practice to stimulate the C-peptide response. The glucagon stimulation test (GST) is a standard measure of endogenous insulin secretion. In GST, $1 \mathrm{mg}$ of glucagon is injected intravenously, and the CPR is measured before and 6 minutes after the injection. In the meal tolerance test (MTT), which is regarded as a physiological stimulating test, normal or standard mixed

Department of Internal Medicine, Wakayama Rosai Hospital, Japan

Received for publication February 3, 2020; Accepted for publication March 30, 2020

Correspondence to Dr. Hisao Wakasaki, wakasaki@wakayama-med.ac.jp 
liquid meal is ingested in the morning with timed measurements of the CPR over the subsequent two to four hours. Greenbaum et al. reported that the mixed MTT is sensitive, providing a higher post-stimulus C-peptide response than GST, and is a reproducible method for measuring the residual $\beta$-cell function in clinical trials in type 1 diabetes (2). Fujioka et al. carried out the normal MTT using a caloriecontrolled breakfast and the GST and then calculated the change in the CPR from the baseline to 6 minutes after the glucagon injection or 120 minutes after the meal. In that study, the CPR increment in the normal MTT was greater than that in the GST (3). This was attributed to the normal meal causing both a sustained plasma glucose (PG) level and an increased incretin effect, promoting greater insulin secretion than an intravenous stimulus through gastric inhibitory polypeptide (GIP) and glucagon-like peptide-1 (GLP-1).

We performed the MTT using a test meal with multiple timed measurements of the serum CPR based on the oral glucose tolerance test over 180 minutes. We also tested the correlation of various CPR-related indices and clinical factors in hospitalized patients with type 2 diabetes mellitus.

\section{Materials and Methods}

\section{Subjects}

The study subjects were patients with type 2 diabetes mellitus, who were admitted to Wakayama Rosai Hospital for diabetes management and education from 2018 to 2019. We excluded subjects with pancreatic disease, with ketoacidosis, with current anti-cancer chemotherapy, with active infectious disease, taking glucocorticoids, with liver disease and with chronic kidney disease, in which the estimated glomerular filtration rate (eGFR) was below $60 \mathrm{~mL} / \mathrm{min} / 1.73$ $\mathrm{m}^{2}$. The final study population consisted of 68 patients.

\section{Methods}

Participants underwent an MTT following an overnight fast. Subjects ingested a test meal (215 g of Calorie-Mate jelly; Otsuka Pharmaceutical, Tokyo, Japan; $100 \mathrm{~mL}$ of yogurt; Yakult Honsha, Tokyo, Japan; $11 \mathrm{~g}$ of plain biscuits; Morinaga, Tokyo, Japan) at 7:30 in the morning. One serving of the test meal provides $346 \mathrm{kcal}$ containing $60.7 \mathrm{~g}$ of carbohydrates, $13.3 \mathrm{~g}$ of protein and $8.2 \mathrm{~g}$ of lipids. Venous blood samples were obtained at $0,30,60,120$ and 180 minutes for the determination of the plasma glucose and serum CPR concentrations. Levels of glycated hemoglobin (HbA1 c) and the eGFR were measured using blood samples at 0 minute. Urinary $\mathrm{C}$-peptide ( $\mathrm{u}-\mathrm{CPR}$ ) was measured in urine collected over 24 hours. The C-peptide index (CPI) was calculated by the following formula: $100 \times$ CPR $(\mathrm{ng} / \mathrm{mL}) /$ plasma glucose $(\mathrm{mg} / \mathrm{dL})$. Participants continued to take their usual medications and insulin injections. We interviewed the patients for medication and measured the HbA1c at six months after discharge to assess glycemic control.
Plasma glucose was measured by glucose oxidase methods (GA-1171; Arkray, Kyoto, Japan), the CPR was measured by an electrochemiluminescence immunoassay (cobas e411; Roche Diagnostics, Tokyo, Japan), HbA1c was measured by high-performance liquid chromatography (HA-8180 $\mathrm{T}$; Arkray), and the eGFR was measured by enzymatic methods (JCA-BM6050; JOEL, Tokyo, Japan).

\section{Statistical analyses}

Data are presented as the mean \pm standard deviation (SD). A simple linear regression analysis was used to assess the correlation. Differences in mean values were determined using an unpaired $t$-test and considered statistically significant at $p<0.05$. Statistical analyses were performed with EZR (Saitama Medical Center, Jichi Medical University, Saitama, Japan), which is a graphical user interface for $\mathrm{R}$ (The $\mathrm{R}$ Foundation for Statistical Computing, Vienna, Austria) (4).

\section{Results}

The baseline clinical characteristics of the participants, including medication at baseline, the number of patients in each treatment and the average dose of insulin, are presented in Table 1. Fig. 1 shows the time response curve of plasma glucose (Fig. 1A) and C-peptide (Fig. 1B) during the MTT in subjects with type 2 diabetes. The peak plasma glucose response occurred at 60 minutes, and the peak CPR response occurred at 120 minutes. In healthy non-obese subjects, both the peak PG and CPR responses occurred at 30 minutes under the same protocol (unpublished observation).

The correlation between the clinical factors and Cpeptide-related indices is presented in Table 2. The Cpeptide value at 0 minute (CPR 0 minute) was positively correlated with the body mass index. The urinary C-peptide excretion for 24 hours (u-CPR) showed a strongly positive correlation with CPR 0 minute (Fig. 2). The correlation between the serum C-peptide value at 120 minutes after a meal (CPR 120 minutes) and u-CPR was less strong than that between CPR 0 min and u-CPR.

We calculated the total CPR $(\Sigma C P R)$ as area under the curve of CPR responses during the MTT using the trapezoidal rule (5). The $\Sigma$ CPR was the best correlated with CPR 120 minutes (Fig. 3). The CPR difference between baseline and 120 minutes after meal $(\triangle \mathrm{CPR})$ was strongly correlated with CPR 120 minutes and CPI 120 minutes, however the correlation between $\triangle \mathrm{CPR}$ and fasting $\mathrm{CPR}$ proved to be weak (Table 2).

The need for insulin and medication for glycemic control at six months after discharge are presented in Table 3. Among the 68 subjects, $26(38 \%)$ were being treated with insulin, and $40(60 \%)$ were being treated with oral hypoglycemic agent (OHA) and/or glucagon like peptide-1 receptor agonist (GLP-1RA) at 6 months after discharge. The mean HbA1c level at 6 months after discharge was significantly higher in subjects with insulin therapy than in those without insulin therapy $(8.04 \%$ vs. $7.21 \%)$. 
Table 1. Clinical Characteristics of the Study Participants.

\begin{tabular}{|c|c|}
\hline $\mathbf{N}$ & 68 \\
\hline Male/female & $38 / 30$ \\
\hline Age (years) & $63.9 \pm 13.3$ \\
\hline BMI $\left(\mathrm{kg} / \mathrm{m}^{2}\right)$ & $25.6 \pm 4.3$ \\
\hline Duration of diabetes mellitus (years) & $12.7 \pm 9.9$ \\
\hline $\operatorname{HbA1c}(\%)$ & $9.76 \pm 2.26$ \\
\hline FPG $\mathrm{mg} / \mathrm{dL}(\mathrm{mmol} / \mathrm{L})$ & $151 \pm 46.1(8.38 \pm 2.55)$ \\
\hline fCPR ng/mL (mmol/L) & $2.06 \pm 0.95(0.682 \pm 0.314)$ \\
\hline eGFR $\left(\mathrm{mL} / \mathrm{min} / 1.73 \mathrm{~m}^{2}\right)$ & $81.0 \pm 20.6$ \\
\hline Medication at baseline & Number of patients in each treatment \\
\hline Diet only & 11 \\
\hline OHA alone & 24 \\
\hline single & $4(\mathrm{DP}), 1(\mathrm{M}), 1(\mathrm{SU}), 1(\mathrm{SG})$ \\
\hline double & $5(\mathrm{DP}+\mathrm{M}), 1(\mathrm{DP}+\mathrm{SU}), 1(\mathrm{~A}+\mathrm{DP}), 1(\mathrm{~A}+\mathrm{SU})$ \\
\hline triple & $3(\mathrm{DP}+\mathrm{M}+\mathrm{SU}), 2(\mathrm{DP}+\mathrm{M}+\mathrm{SG}), 1(\mathrm{M}+\mathrm{SG}+\mathrm{SU})$ \\
\hline more & $1(\mathrm{~A}+\mathrm{DP}+\mathrm{M}+\mathrm{SU}), 1(\mathrm{DP}+\mathrm{M}+\mathrm{DP}+\mathrm{SU})$ \\
\hline Insulin alone & 24 \\
\hline Basal insulin & 2 (mean dose $7 \mathrm{U})$ \\
\hline Bolus insulin & 14 ( mean dose $27.1 \mathrm{U})$ \\
\hline Basal and bolus insulin & 7 (mean dose Basal 15U; Bolus 38.4U) \\
\hline Mixed insulin & 1 (dose $30 \mathrm{U})$ \\
\hline Insulin with OHA & $\begin{array}{l}7 \text { (A+DP+Bolus:28U, DP+Bolus+Basal:48U, DP+M+Basal:6U, } \\
\text { M+Bolus:14U, M+Bolus:12U, SU+Bolus:18U, M+Bolus:8U) }\end{array}$ \\
\hline Insulin with GLP1-RA & 2 (Bolus:23U, Basal:16U) \\
\hline
\end{tabular}

The clinical variables and CPR-related indices were compared between patients who did and did not need insulin therapy at six months after discharge (Table 4). Patients who needed insulin therapy showed a significantly lower $\triangle \mathrm{CPR}$ than those who did not need insulin therapy.

\section{Discussion}

The standardized mixed MTT reportedly provides reproducible and reliable measures of the $\beta$-cell function for use in large clinical trials (6). However, a full-scale mixed MTT is not often performed in routine clinical practice because of frequent blood samplings, long test time up to five hours and need for minimal model approaches for the data analysis. The simplified MTT was reported to be useful, in which the CPR level at 120 minutes after calorie-controlled breakfast was suggested to be a good index for identifying patients with non-obese type 2 diabetes requiring multiple daily insulin injections during hospitalization (7).

However, previous studies have reported that various CPR-related indices are useful markers for predicting insulin requirement in type 2 diabetes. Asano et al. reported that the ratio of 24-hours urinary CPR excretion to fasting PG and fasting CPI were useful indices for future insulin requirement (8). Funakoshi et al. reported that the fasting CPI was a superior marker for selecting insulin therapy to achieve good glycemic control during admission (9). Saisho et al. reported that the postprandial CPI at 120 minutes was the best predictive marker for future insulin therapy (10). Okuno et al. reported that CPR-related indices can be useful markers reflecting both insulin sensitivity and disease duration in type 2 diabetes (11). Sonoda et al. reported that the fasting CPR value and 24-hours urinary CPR excretion predicted improved $\mathrm{HbA} 1 \mathrm{c}$ values at 6 months after hospitalization for diabetes management (12).

The present study differs from previous ones in the patient background characteristics, test meal preparation, sampling times in the MTT and evaluation of insulin therapy. Many previous studies used a calorie-controlled breakfast for stimulation and performed 2 blood samplings (before and 120 minutes after breakfast) $(3,7,10)$. In the present study, by contrast, we prepared a test meal for standardization instead of a calorie-controlled meal. We performed multiple blood samplings based on the oral glucose tolerance test to clarify the usefulness of the MTT in routine clinical settings. Sampling the blood multiple times has the advantage of enabling the evaluation of the post-stimulated total CPR secretion as the area under the curve during the MTT.

In our study participants, the peak plasma glucose response occurred at 60 minutes, and the peak CPR response occurred at 120 minutes. The peak responses of plasma glucose and insulin after glucose ingestion were reportedly shifted to later times in diabetic patients than in non-diabetic subjects (13). We should take care when evaluating the 
postprandial CPR or postprandial CPI response at a single point in time, as the peak times may not be the same. Our

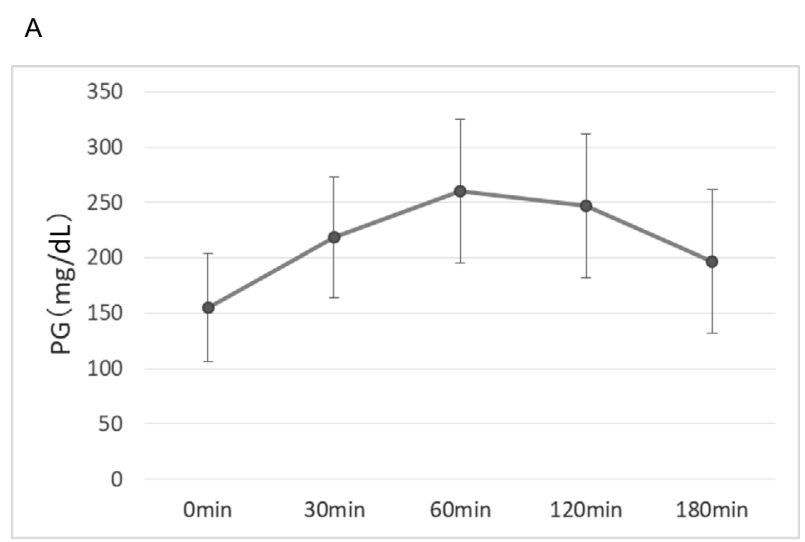

B

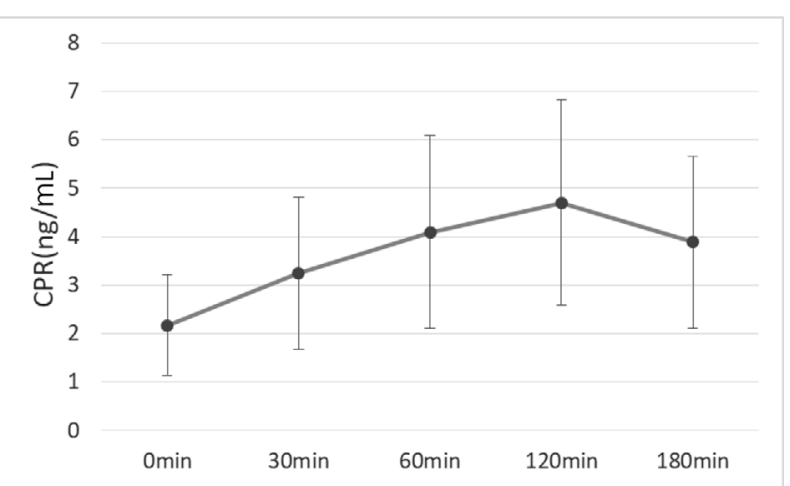

Figure 1. Plasma glucose (A) and serum C-peptide (B) concentrations during meal tolerance test. Data are presented as mean \pm SD. CPR: C-peptide immunoreactivity, PG: plasma glucose. CPR: $1 \mathrm{ng} / \mathrm{mL}=0.3312 \mathrm{mmol} / \mathrm{L}$ PG: $100 \mathrm{mg} / \mathrm{dL}=5.551$ $\mathrm{mmol} / \mathrm{L}$. study can help clarify which sampling timing in the MTT gives the most meaningful information concerning patients with type 2 diabetes mellitus.

In the present study, the CPR at baseline was positively correlated with both the BMI and u-CPR. This is in agreement with the findings of a previous study, where there was a good correlation between the fasting CPR and 24-hours uCPR before and after diabetes treatment (14). Unexpectedly, the correlation between CPR 120 minutes and $\mathrm{u}-\mathrm{CPR}$ was weaker than that between CPR 0 minute and $\mathrm{u}-\mathrm{CPR}$ in our study.

The $\Sigma$ CPR represents the area under the curve of the CPR response in the MTT and is supposed to indicate the foodstimulated endogenous insulin secretion. No previous studies have reported the $\Sigma C P R$ value in the MTT. Our data showed that the $\Sigma C P R$ was very strongly correlated with the CPR 120 minutes in the MTT, although other indices, such as the CPR 0 minutes and CPI 120 minutes, showed relatively strong correlations with the $\Sigma \mathrm{CPR}$ as well. This result supports the idea that the CPR value at a single point (120 minutes) in the MTT may represent the total insulin secretion after meal in patients with type 2 diabetes mellitus.

In previous studies, the need for insulin was determined at variety of time points, ranging from the end of hospitalization to several years after discharge $(7,8,10)$. We interviewed our present patients for disease management and evaluated the HbA1c at six months after discharge. At that point, $38 \%$ of the patients required insulin therapy, and insulin-treated patients showed significantly higher $\mathrm{HbAlc}$ values than the insulin-untreated patients. The difference in the CPR between baseline and 120 minutes after meal $(\triangle \mathrm{CPR})$ indicates the additional endogenous insulin secretion induced by meal stimulation. The average $\triangle \mathrm{CPR}$ at discharge was significantly lower in the insulin-treated group

Table 2. Correlations between Clinical Variables and C-peptide Related Indices.

\begin{tabular}{|c|c|c|c|c|c|c|c|c|c|c|c|c|c|}
\hline & BMI & Duration & $\begin{array}{c}\mathrm{HbA} 1 \mathrm{c} \text { at } \\
\text { baseline }\end{array}$ & $\begin{array}{l}\text { HbA1c } \\
\text { after } 6 \mathrm{M}\end{array}$ & $\begin{array}{c}P G \\
0 \mathrm{~min}\end{array}$ & $\begin{array}{c}P G \\
120 \mathrm{~min}\end{array}$ & $\begin{array}{c}\text { CPR } \\
0 \mathrm{~min}\end{array}$ & $\begin{array}{c}\text { CPR } \\
120 \mathrm{~min}\end{array}$ & $\begin{array}{c}\text { CPI } \\
0 \mathrm{~min}\end{array}$ & $\begin{array}{c}\text { CPI } \\
120 \mathrm{~min}\end{array}$ & $\mathrm{u}-\mathrm{CPR}$ & $\Delta \mathrm{CPR}$ & $\Sigma \mathrm{CPR}$ \\
\hline BMI & & -0.364 & -0.129 & -0.100 & 0.06 & -0.070 & 0.505 & 0.418 & 0.393 & 0.371 & 0.400 & 0.211 & 0.462 \\
\hline Duration & -0.364 & & -0.133 & 0.268 & 0.042 & 0.056 & -0.290 & -0.353 & -0.284 & -0.333 & -0.363 & -0.264 & -0.333 \\
\hline $\mathrm{HbA} 1 \mathrm{c}$ at baseline & -0.129 & -0.133 & & 0.160 & 0.252 & 0.376 & -0.01 & -0.12 & -0.244 & -0.347 & 0.294 & -0.149 & -0.080 \\
\hline HbA1c after $6 \mathrm{M}$ & -0.100 & 0.268 & 0.16 & & 0.153 & 0.031 & -0.183 & -0.390 & -0.224 & -0.362 & -0.229 & -0.373 & -0.371 \\
\hline PG 0 min & 0.06 & 0.042 & 0.252 & 0.153 & & 0.706 & 0.209 & -0.089 & -0.423 & -0.433 & 0.32 & -0.243 & 0.01 \\
\hline PG $120 \mathrm{~min}$ & -0.070 & 0.056 & 0.376 & 0.031 & 0.706 & & 0.044 & -0.047 & -0.415 & -0.583 & 0.096 & -0.031 & 0.043 \\
\hline CPR 0 min & 0.505 & -0.290 & -0.01 & -0.183 & 0.209 & 0.044 & & 0.622 & 0.704 & 0.495 & 0.723 & 0.16 & 0.751 \\
\hline CPR $120 \mathrm{~min}$ & 0.418 & -0.353 & -0.12 & -0.390 & -0.089 & -0.047 & 0.622 & & 0.538 & 0.752 & 0.515 & 0.872 & 0.970 \\
\hline CPI 0 min & 0.393 & -0.284 & -0.244 & -0.224 & -0.423 & -0.415 & 0.704 & 0.538 & & 0.691 & 0.303 & 0.238 & 0.591 \\
\hline CPI $120 \mathrm{~min}$ & 0.371 & -0.333 & -0.347 & -0.362 & -0.433 & -0.583 & 0.495 & 0.752 & 0.691 & & 0.302 & 0.639 & 0.731 \\
\hline $\mathrm{u}-\mathrm{CPR}$ & 0.400 & -0.363 & 0.294 & -0.229 & 0.32 & 0.096 & 0.723 & 0.515 & 0.303 & 0.302 & & 0.180 & 0.631 \\
\hline$\Delta \mathrm{CPR}$ & 0.211 & -0.264 & -0.149 & -0.373 & -0.243 & -0.031 & 0.16 & 0.872 & 0.238 & 0.639 & 0.180 & & 0.753 \\
\hline$\Sigma \mathrm{CPR}$ & 0.462 & -0.333 & -0.080 & -0.371 & 0.01 & 0.043 & 0.751 & 0.970 & 0.591 & 0.731 & 0.631 & 0.753 & \\
\hline
\end{tabular}

BMI: body mass index, CPI: C-peptide index, CPI 0 min: CPI at 0 min in MTT, CPI120 min: CPI at 120 min in MTT, CPR: C-peptide immunoreactivity, CPR 0 min: CPR at 0 min in MTT, CPR 120 min: CPR at 120 min in MTT, Duration: duration of diabetes mellitus, HbA1c: glycated hemoglobin, HbA1c after 6M: HbA1c at 6 months after discharge, PG: plasma glucose, PG0 min: PG at 0 min in MTT, PG120 min: PG at 120 min in MTT, u-CPR: urinary CPR excretion for $24 \mathrm{~h}, \Sigma \mathrm{CPR}$ : area under the curve of CPR response from zero to $180 \mathrm{~min}$ in MTT, $\Delta \mathrm{CPR}$ : incremental CPR value from baseline to 120 min in MTT, Pearson's correlation coefficient (r) is shown. 
than in the insulin-untreated group, indicating that the mealstimulated insulin secretion ability was reduced in insulintreated patients.

Previous papers have reported that the fasting CPR, fasting CPI, postprandial CPR and postprandial CPI are useful markers for predicting insulin requirement in type 2 diabetes. Although the methods for determining the insulin requirement have differed among studies, the findings concerning the usefulness of these indices agree with our present observations. In the present study, the incremental CPR level from the baseline to 120 minutes in the MTT was suggested to be another useful index for predicting insulin necessity in patients with type 2 diabetes mellitus, although other indices, such as the CPR 0 minute, CPI 0 minute, CPI 120 minutes, $\Sigma$ CPR and Duration, showed significant differences between the insulin-treated group and insulinuntreated group. No previous papers reported the usefulness of the $\triangle \mathrm{CPR}$ during the MTT for predicting insulin therapy.

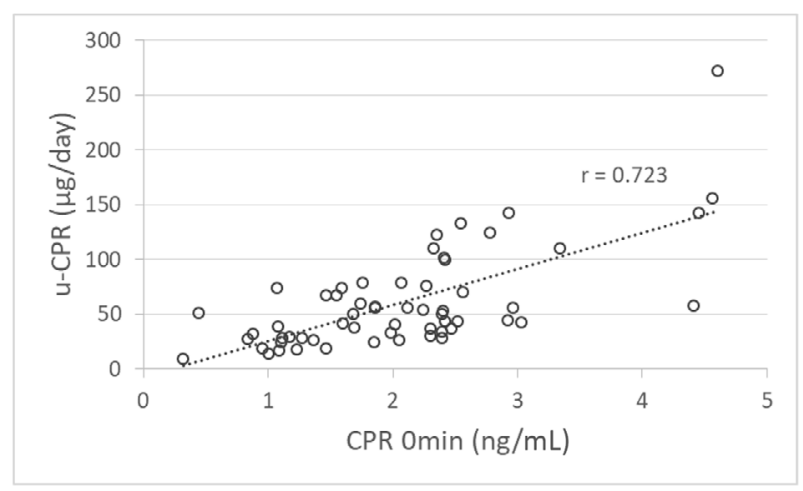

Figure 2. The correlation between the fasting CPR and urinary CPR excretion for $\mathbf{2 4}$ hours. Pearson's correlation coefficient ( $r$ ) is shown. CPR 0 min, serum CPR value at 0 minute in the MTT; u-CPR, urinary CPR excretion for 24 hours. CPR: 1 $\mathrm{ng} / \mathrm{mL}=0.3312 \mathrm{mmol} / \mathrm{L}$.
However, a previous study suggested that the $\triangle \mathrm{CPR}$ was more useful than CPR at 120minutes after meal for estimating the insulin secretory ability in patients with renal dysfunction (7). The serum CPR value can be falsely elevated in patients with chronic kidney diseases (CKD) due to the reduced C-peptide clearance by the kidney. Further studies are needed to ascertain the usefulness of the $\triangle \mathrm{CPR}$ value in CKD patients with type 2 diabetes mellitus.

Taken together, these findings indicated that, among various indices, the CPR values at baseline and 120 minutes in the MTT are essential measurements. However, we were unable to confirm which index was the best predictive marker for insulin necessity in this study.

Several limitations associated with the present study warrant mention. The sample size was small, and this study was conducted in one hospital with specific protocols for test

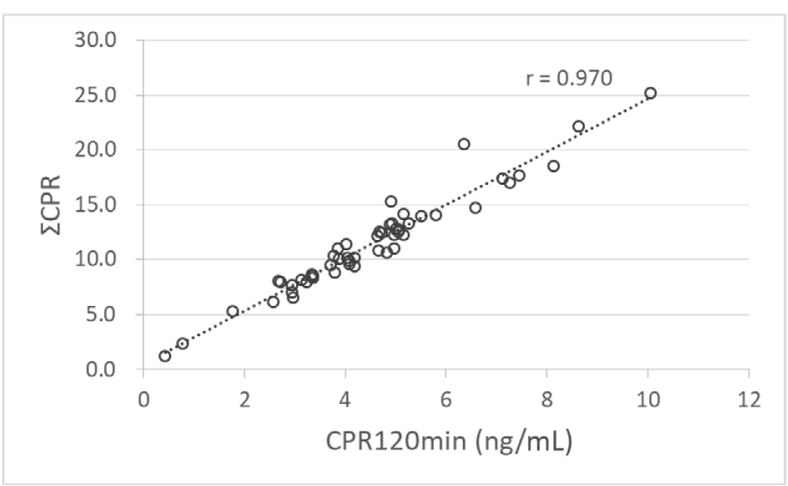

Figure 3. The correlation between the serum CPR level at 120 minutes in the MTT and area under the curve of CPR response during the MTT. Pearson's correlation coefficient (r) is shown. CPR 120 minutes, serum C-peptide value at 120 minutes in the MTT; $\Sigma$ CPR, area under the curve of CPR response from 0 to 180 minutes in the MTT. CPR: $1 \mathrm{ng} / \mathrm{mL}=0.3312$ $\mathrm{mmol} / \mathrm{L}$.

Table 3. Insulin Necessity and Glycemic Control at 6 Months after Discharge.

\begin{tabular}{|c|c|c|c|c|}
\hline & \multicolumn{2}{|c|}{ Insulin therapy (-) } & \multicolumn{2}{|r|}{ Insulin therapy (+) } \\
\hline \multirow[t]{9}{*}{ Medication } & & 42 & & 26 \\
\hline & OHA alone & 36 & Insulin alone & 17 \\
\hline & single & 4(DP), 3(M), 2(SU), 1(SG), 1(A) & Basal insulin & $2($ mean dose $19 \mathrm{U})$ \\
\hline & double & $\begin{array}{l}7(\mathrm{DP}+\mathrm{M}), 2(\mathrm{DP}+\mathrm{SU}), 1(\mathrm{~A}+\mathrm{M}) \\
1(\mathrm{~A}+\mathrm{SU}), 1(\mathrm{M}+\mathrm{SU}), 1(\mathrm{M}+\mathrm{SG})\end{array}$ & Bolus insulin & $1($ dose $34 \mathrm{U})$ \\
\hline & triple & $\begin{array}{c}3(\mathrm{DP}+\mathrm{M}+\mathrm{SU}), 2(\mathrm{DP}+\mathrm{M}+\mathrm{SG}) \\
1(\mathrm{M}+\mathrm{SG}+\mathrm{SU}), 1(\mathrm{~A}+\mathrm{DP}+\mathrm{M})\end{array}$ & Basal and bolus insulin & 13(mean dose Basal 13.2U; Bolus 30.8U) \\
\hline & more & $5(\mathrm{~A}+\mathrm{DP}+\mathrm{M}+\mathrm{SU})$ & Mixed insulin & $2($ mean dose $14 \mathrm{U})$ \\
\hline & GLP1-RA alone & 2 & Insulin with OHA & 6(M+DP+Bolus28U+Basal6U, M+Bolus12U, \\
\hline & GLP1-RA with OHA & 2(M+GLP1-RA) & & $\begin{array}{c}\text { M+SG+Bolus20U, M+DP+SU+Mix8U, } \\
\text { SU+Bolus54U, M+DP+Basal6U) }\end{array}$ \\
\hline & Diet only & 2 & Insulin and GLP1-RA & $\begin{array}{l}\text { 2(GLP1-RA+Bolus42U, } \\
\text { GLP1-RA+Basal22U) }\end{array}$ \\
\hline $\mathrm{HbA1c}(\%)$ & & $7.21 \pm 1.07 *$ & & $8.04 \pm 1.58$ \\
\hline
\end{tabular}

Insulin therapy (+): patients who need insulin therapy at six months since discharge, Insulin therapy (-): patients who do not need insulin therapy at six months since discharge, HbA1c: glycated hemoglobin, OHA: oral hypoglycemic agents, A: $\alpha$-glucosidase inhibitor, DP: dipeptidyl peptidase-4 inhibitor, GLP-1RA: glucagon-like peptide-1 receptor agonist, M: metformin, SG: sodium-glucose co-transporter 2 inhibitor, SU: sulfonylurea, U: unit of insulin. *p<0.01 
Table 4. Comparison of Clinical Variables and CPR Related Indices between Patients Who Need Insulin Therapy and Who Do Not Need Insulin Therapy at 6 Months since Discharge.

\begin{tabular}{lccc}
\hline & Insulin therapy $(-)$ & Insulin therapy $(+)$ & $\mathrm{p}$ \\
\hline HbA1c $(\%)$ at baseline & $9.54 \pm 1.95$ & $10.12 \pm 2.67$ & 0.17 \\
CPR0 min $\mathrm{ng} / \mathrm{mL}(\mathrm{mmol} / \mathrm{L})$ & $2.31 \pm 0.91(0.76 \pm 0.30)$ & $1.65 \pm 0.86(0.54 \pm 0.28)$ & $<0.01$ \\
CPR120 $\mathrm{min} \mathrm{ng} / \mathrm{mL}(\mathrm{mmol} / \mathrm{L})$ & $5.32 \pm 2.15(1.76 \pm 0.71)$ & $3.58 \pm 1.54(1.18 \pm 0.51)$ & $<0.01$ \\
$\Delta$ CPR $\mathrm{ng} / \mathrm{mL}(\mathrm{mmol} / \mathrm{L})$ & $3.00 \pm 1.61(0.99 \pm 0.53)$ & $1.93 \pm 1.18(0.63 \pm 0.39)$ & $<0.01$ \\
CCPR & $12.63 \pm 4.50$ & $9.27 \pm 3.69$ & $<0.01$ \\
CPI 0 min & $1.70 \pm 0.79$ & $1.05 \pm 0.54$ & $<0.01$ \\
CPI $120 \mathrm{~min}$ & $2.68 \pm 1.56$ & $1.56 \pm 0.72$ & $<0.01$ \\
PG0 $\mathrm{min} \mathrm{mg} / \mathrm{dL}(\mathrm{mmol} / \mathrm{L})$ & $142.7 \pm 37.6(7.92 \pm 2.08)$ & $164.9 \pm 55.2(9.15 \pm 3.06)$ & 0.039 \\
PG120 min mg/dL (mmol/L) & $224.7 \pm 72.0(12.47 \pm 3.99)$ & $245.9 \pm 78.1(13.64 \pm 4.33)$ & 0.134 \\
u-CPR $(\mu \mathrm{g} / \mathrm{day})$ & $64.8 \pm 51.9$ & $49.6 \pm 31.8$ & 0.045 \\
BMI $\left(\mathrm{kg} / \mathrm{m}^{2}\right)$ & $26.5 \pm 4.3$ & $24.2 \pm 3.9$ & 0.014 \\
Duration $($ year $)$ & $10.4 \pm 9.8$ & $16.3 \pm 9.1$ & $<0.01$ \\
\hline
\end{tabular}

BMI: body mass index, CPI: C-peptide index, CPI 0 min: CPI at 0 min in MTT, CPI120 min: CPI at 120 min in MTT, CPR: C-peptide immunoreactivity, CPR $0 \mathrm{~min}$ : CPR at $0 \mathrm{~min}$ in MTT, CPR $120 \mathrm{~min}$ : CPR at 120 min in MTT, Duration: duration of diabetes mellitus, HbA1c: glycated hemoglobin, PG: plasma glucose, PG0 min: PG at $0 \mathrm{~min}$ in MTT, PG120 min: PG at $120 \mathrm{~min}$ in MTT, u-CPR: urinary CPR excretion for $24 \mathrm{~h}$, ECPR: area under the curve of CPR response from zero to $180 \mathrm{~min}$ in MTT, $\triangle \mathrm{CPR}$ : incremental CPR value from baseline to $120 \mathrm{~min}$ in MTT

meal preparation and blood sampling times. Participants showed a very high $\mathrm{HbA1c}$ value at the baseline. The change in the CPR in the MTT is reported to be potentially underestimated in the hyperglycemic state (3). Baseline medications might have affected the CPR responses in the MTT, as anti-diabetic drugs, such as sulfonylureas, dipeptidyl peptidase (DPP)-4 inhibitors and GLP1-RA, stimulate endogenous insulin secretion. A previous report found that giving anti-diabetic drugs to patients undergoing the MTT has little effect on its ability to detect endogenous insulin secretion (3). Insulin therapy is also suggested to affect the CPR response in the MTT; however, a previous study reported that exogenous insulin did not influence the stimulated CPR levels in type 2 diabetic subjects (15). The selection bias of hypoglycemic agents, including insulin, could not be excluded, although the patients were treated individually according to the Japan Diabetes Society (JDS) treatment guide for diabetes (16).

In conclusion, fasting CPR was correlated with 24-hours urinary CPR excretion. The CPR value at 120 minutes in the MTT was strongly correlated with the meal-stimulated total CPR secretion. The incremental CPR value from baseline to 120 minutes after a meal was one of the predictors for insulin necessity at 6 months after hospitalization. The measurement of plasma C-peptide at 0 and 120 minutes in the MTT provides essential information for the clinical management of patients with type 2 diabetes mellitus.

Written informed consent was obtained from all patients prior to their participation in this study.

The authors state that they have no Conflict of Interest (COI).

\section{Acknowledgement}

The authors thank Naoto Tanigawa, Yumi Mori and Etsuko Maeda for their help and valuable discussions.

\section{References}

1. Jones AG, Hattersley AT. The clinical utility of C-peptide measurement in the care of patients with diabetes. Diabet Med 30: 803$817,2013$.

2. Greenbaum CJ, Mandrup-Poulsen T, McGee PF, et al.; Type 1 Diabetes Trial Net Research Group, European C-Peptide Trial Study Group. Mixed-meal tolerance test versus glucagon stimulation test for the assessment of beta-cell function in therapeutic trials in type1 diabetes. Diabetes Care 31: 1966-1971, 2008.

3. Fujioka Y, Okura T, Sumi K, et al. Normal meal tolerance test is preferable to the glucagon stimulation test in patients with type2 diabetes that are not in a hyperglycemicstate: comparison with the change of C-peptide immunoreactivity. J Diabetes Investig 9: 274278, 2018.

4. Kanda Y. Investigation of the freely-available easy-to-use software "EZR" (Easy R) for medical statistics. Bone Marrow Transplant 48: 452-458, 2013.

5. Brouns F, Bjorck I, Frayn KN, et al. Glycaemic index methodology. Nutr Res Rev 18: 145-171, 2005.

6. Shankar SS, Vella A, Raymond RH, et al.; The Foundation for the National Institutes of Health $\beta$-Cell Project Team. Standardized mixed-meal tolerance and Arginine stimulation tests provide reproducible and complementary measures of $\beta$-Cell function: results from the Foundation for the National Institutes of Health Biomarkers Consortium Investigative Series. Diabetes Care 39: 1602-1613, 2016.

7. Fujiwara D, Takahashi K, Suzuki T, et al. Postprandial serum Cpeptide value is the optimal index to identify patients with nonobese type 2 diabetes who require multiple daily insulin injection: analysis of C-peptide values before and after short-term intensive insulin therapy. J Diabetes Investig 4: 618-625, 2013.

8. Asano $T$, Kawamura M, Watanabe $T$, et al. Indices of urinary and serum C-peptide corrected with fasting plasma glucose for decision-making of insulin therapy in type 2 diabetes-validation 
and comparison. J Jpn Diab Soc 51: 759-763, 2008 (in Japanese, Abstract in English).

9. Funakoshi S, Fujimoto S, Hamasaki A, et al. Utility of indices using C-peptide levels for indication of insulin therapy to achieve good glycemic control in Japanese patients with type 2 diabetes. J Diabetes Investig 2: 297-303, 2011.

10. Saisho Y, Kou K, Tanaka K, et al. Postprandial serum C-peptide to plasma glucose ratio as a predictor of subsequent insulin treatment in patients with type2 diabetes. Endocr J 58: 315-322, 2011.

11. Okuno Y, Sakaguchi K, Komada H, et al. Correlation of serum CPR to plasma glucose ratio with various indices of insulin secretion and diseases duration in type 2 diabetes. Kobe J Med Sci 59: E44-E53, 2013.

12. Sonoda R, Tanaka K, Kikuchi T, et al. C-peptide level in fasting plasma and pooled urine predicts hba1c after hospitalization in patients with type 2 diabetes mellitus. PLoS One 11: e0147303, 2016.

13. Rizza RA. Pathogenesis of fasting and postprandial hyperglycemia in type 2 diabetes: implications for therapy. Diabetes 59: 2697 2707, 2010.

14. Suzuki T, Satoh N, Suzuki S, Kajinuma H, Kuzuya N. Changes in 24-hr urinary C-peptide excretion and serum C-peptide response after meal load in non-insulin dependent diabetic patients following treatment. J Jpn Diab Soc 30: 803-809, 1987 (in Japanese, Abstract in English).

15. Albareda M, Rigla M, Rodríguez-Espinosa J, et al. Influence of exogenous insulin on C-peptide levels in subjects with type 2 diabetes. Diabetes Res Clin Pract 68: 202-206, 2005.

16. Treatment Guide for Diabetes 2018-2019. Japan Diabetes Society Eds. Bunkodo, Japan, 2018.

The Internal Medicine is an Open Access journal distributed under the Creative Commons Attribution-NonCommercial-NoDerivatives 4.0 International License. To view the details of this license, please visit (https://creativecommons.org/licenses/ by-nc-nd/4.0/).

(C) 2020 The Japanese Society of Internal Medicine

Intern Med 59: 2229-2235, 2020 